\title{
Preliminary Characterization of El Tor Vibriophage M4
}

\author{
Sayani Das Amar N. Ghosh

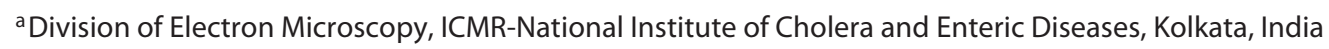

\author{
Keywords \\ Vibrio cholerae - Bacteriophage - Choleraphage . \\ Vibriophage M4 · Electron microscopy
}

\begin{abstract}
Aims: The aim of the present study is the preliminary characterization of an El Tor vibriophage M4 (ATCC 51352-B4). Methods: We studied the growth characteristics and sustainability of this phage under various stresses like temperature, $\mathrm{pH}$, and UV. The phage morphology and phage genome were also examined using electron microscopy. $\boldsymbol{R e}$ sults: Sustainability studies showed that the phage is more stable in acidic conditions, which is very uncommon among vibriophages. Studies also showed that M4 is a thermostable phage and it is inactivated by temperatures above $60^{\circ} \mathrm{C}$ but, like other phages, UV has a high inactivating effect on it. Morphological and genomic studies by electron microscopy showed that this phage has a long contractile tail and a big head. The genome is linear and about $120 \mathrm{~kb}$ in length. The genome also has a high packaging density as the value of $\mathrm{Vm}$ (the volume occupied per Da of biological macromolecule) is low for this phage. The phage-bacterial interaction was studied by negative staining as well as ultrathin sectioning methods. Conclusions: M4 belongs to the Myoviridae family and it is generally thermostable. It is prone to destruction by alkali and UV. It also has a large DNA which is densely packed inside of a big capsid.

๑) 2018 S. Karger AG, Basel
\end{abstract}

\section{KARGER}

() 2018 S. Karger AG, Basel

E-Mail karger@karger.com

www.karger.com/int
Cholera is an acute diarrheal disease that can kill a patient within hours ifleft untreated. Among the 7 pandemics of cholera which have killed millions of people across all continents, the current (seventh) pandemic started in South Asia in 1961 and reached Africa in 1971 and the Americas in 1991 [1]. It is estimated that each year there are 1.3-4.0 million cases of cholera and 21,000-143,000 deaths worldwide due to cholera [2]. Vibrio cholerae, the causative agent of cholera, has many serogroups but only 2, i.e., $\mathrm{O} 1$ and $\mathrm{O} 139$, can cause the disease in humans [3]. However, all of the recent outbreaks were caused by $V$. cholerae $\mathrm{O} 1$ strains [4]. V. cholerae $\mathrm{O} 1$ has 2 biotypes, i.e., classical and $\mathrm{El} \mathrm{Tor,} \mathrm{and} \mathrm{both} \mathrm{can} \mathrm{cause} \mathrm{cholera} \mathrm{with}$ indistinguishable symptoms. In recent years, infections with the classical biotype of $V$. cholerae $\mathrm{O} 1$ have become rare and have been limited to parts of Bangladesh and India [5], whereas El Tor strains have been responsible for pandemic cholera since 1961.

In the majority of cases cholera is treated by administration of oral rehydration solution and antibiotics, but mass use of antibiotics has led to antimicrobial resistance [1]. For example, the cholera epidemic in Haiti in 2010 is reported to have been caused by the more virulent strains of $V$. cholerae that were resistant to multiple available drugs $[6,7]$. Due to the emergence of antibiotic-resistant bacterial strains there is an extensive search for an alternative treating method. Phage therapy is one such potential alternative and it is gaining a lot of attention through- 
out the world. Bacteria can also form a protective layer (biofilm) around them which is structurally complex and represents a protected mode of growth that allows bacteria to survive in hostile environments [8]. Thus, treating bacterial diseases with bacteriophages can overcome the problem of biofilm-mediated bacterial resistance. Bacteriophages also play a crucial role in tracking down the spread of different epidemics caused by their host bacterium. The use of bacteriophages for the treatment of bacterial infections in humans was proposed earlier by Felix d'Herrel in the beginning of 20th century [9]. Bacteriophages are also capable of replicating their DNA and form structural protein components in a short period of time inside host organisms under much pressurized conditions. This is one of the essential features for fabricating a nano-container which can be used for various purposes such as a delivery system.

In 1993 Chattopadhyay et al. [10] proposed a new phage-typing scheme for El Tor V. cholerae with the help of 5 new vibriophages. The aim of the present study is the characterization of one such new phage, i.e., M4 (ATCC 51352-B4) of El Tor V. cholerae. This study will reveal the physical, morphological, and genome characteristics of the El Tor vibriophage M4. It will also help to understand the stability of this phage under different physical conditions like different temperature zones and $\mathrm{pH}$ values, as well as under UV rays, to evaluate its importance as a potent treatment agent against cholera.

For this study, vibriophage M4 was propagated in logphase El Tor $V$. cholerae strain O1 MAK757 grown in LB broth [11]. The soft agar overlay method was used for preparation of the high-titer phage [11]. The titer was estimated via the plaque assay method. Concentration of the phage sample was done by ultracentrifugation for $1 \mathrm{~h}$ and $30 \mathrm{~min}$ at 25,000 rpm in a Sorvall T-680 rotor at $4{ }^{\circ} \mathrm{C}$. Purification of the phage sample was done via the preformed sucrose step gradient method by ultracentrifugation for $1 \mathrm{~h}$ and $30 \mathrm{~min}$ at 25,000 rpm in a Sorvall Th 880 rotor at $4{ }^{\circ} \mathrm{C}$, followed by dialysis against Tris$\mathrm{MgCl}_{2}$ (0.01-0.005 M, pH 7.4) buffer overnight with 3 successive changes of the buffer as described previously by Chakraborty and colleagues [10]. This lytic phage M4 shows clear and transparent plaques of a diameter around $3.6 \pm 0.4 \mathrm{~mm}$ in $\mathrm{LB}$ propagation medium and at $37^{\circ} \mathrm{C}$ overnight incubation. For a 1-step growth curve of MAK757, $10^{8}$ cells $/ \mathrm{mL}$ were infected with the M4 phage at a multiplicity of infection of 0.1 and incubated at $37^{\circ} \mathrm{C}$ for $5 \mathrm{~min}$ with shaking. It was then centrifuged, the supernatant was removed, and the pellet was resuspended in fresh LB broth. Every $5 \mathrm{~min}, 2$ sets of aliquots were

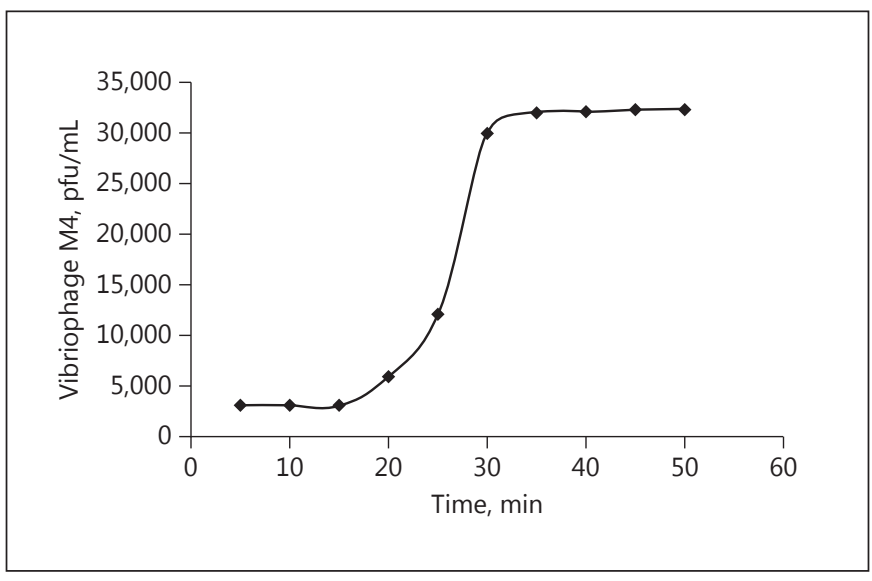

Fig. 1. One-step growth curve of vibriophage M4. The eclipse and latent periods are 15 and $30 \mathrm{~min}$, respectively. pfu, plaque-forming units.

collected. One set was treated with chloroform and the other one was left untreated. Both sets were then assayed for the total phage present. The growth curve of the phage M4 is presented in Figure 1, which shows that the eclipse and latent period are around 15 and $30 \mathrm{~min}$, respectively. The eclipse and latent period for this phage are similar to those of other vibriophages characterized so far, like S20, S5, and e5 [12-14]. The burst size, which is defined as the number of effective plaques produced from each infected cell, is around 10 pfu (plaque-forming units) per infected bacterium, which is low in comparison to others like S20 and e5. The adsorption coefficient for this phage was determined as described by Stent [15] for bacteriophage T4. The exponentially grown bacterial culture was infected with M4 phage at a multiplicity of infection of 0.1 and incubated for $20 \mathrm{~min}$ at $37^{\circ} \mathrm{C}$ with shaking. Aliquots were taken every $2 \mathrm{~min}$ and centrifuged, and the pellet was removed and the free phage in the supernatant was assayed via the serial dilution and plating method. Based on the free phage assessment the adsorption constant was found to be $4.5 \times 10^{-8}$ $\mathrm{mL} / \mathrm{min}$ initially and then it became $2 \times 10^{-9} \mathrm{ml} / \mathrm{min}$. This phage also obeys the biphasic growth kinetics like all other vibriophages, except $\varnothing 149$ [16]; however, the reason behind its biphasic growth kinetics is still unknown.

To assess phage sustainability under various temperature ranges, the phage M4 (concentration $10^{9} \mathrm{pfu} / \mathrm{mL}$ ) was added to fresh LB broth and incubated for $1 \mathrm{~h}$ at temperatures ranging from 20 to $70^{\circ} \mathrm{C}$ at an interval of $10^{\circ} \mathrm{C}$. Assay for the surviving phage was done via the serial dilu- 


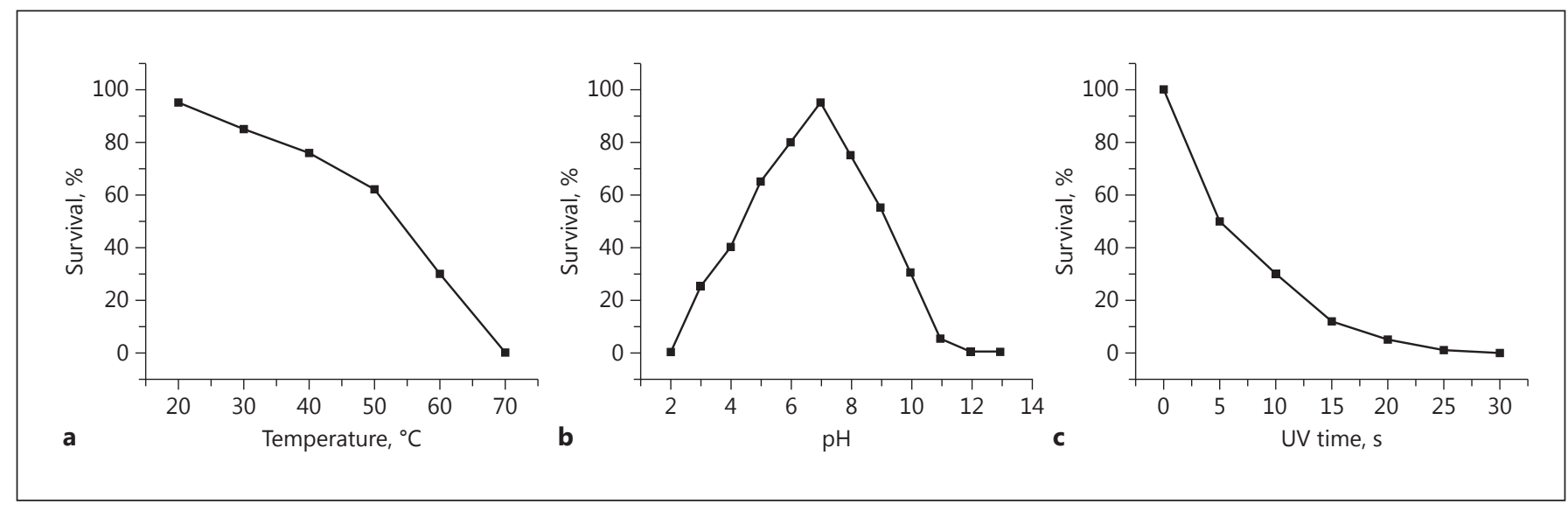

Fig. 2. Sustainability test of the M4 phage under different conditions of temperature, $\mathrm{pH}$, and UV. a Temperature kinetics of phage M4 at different thermal points showing its thermostable nature. $\mathbf{b}$ pH inactivation curve showing that the phage is more stable in acid. c UV inactivation kinetics of phage M4.
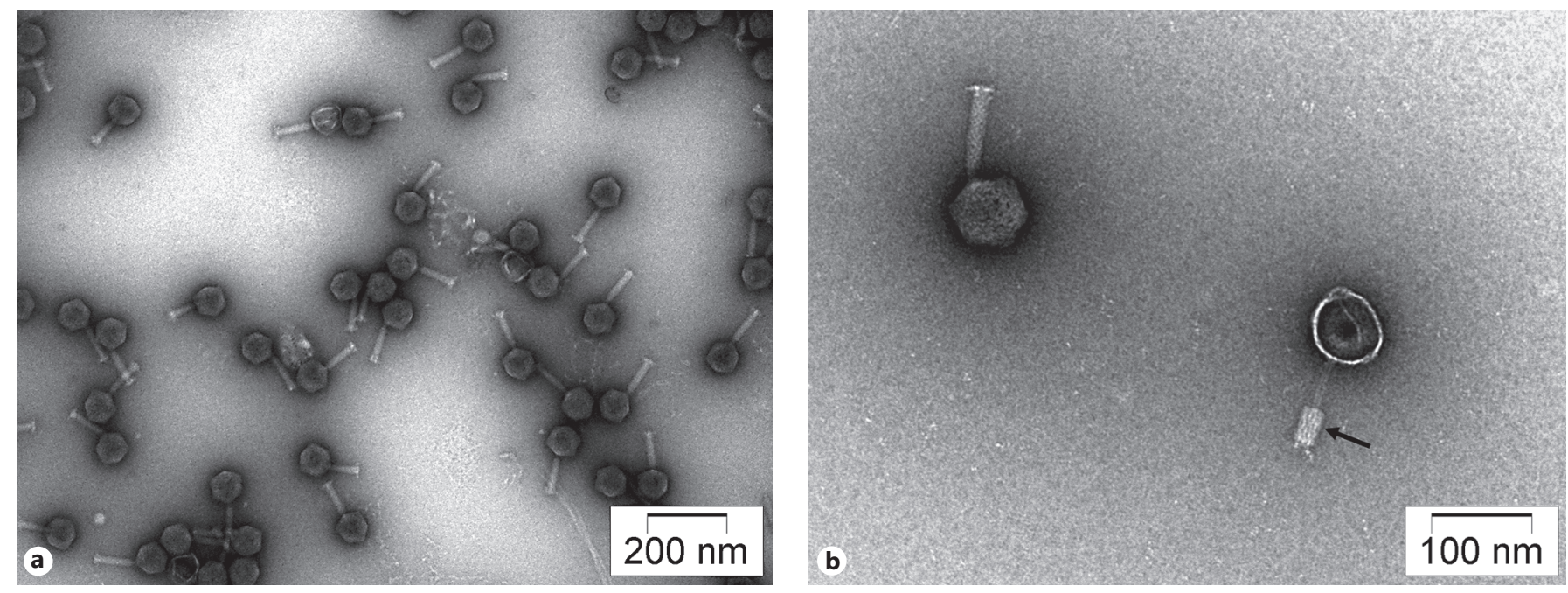

Fig. 3. a Negatively stained image of the M4 phage showing a hexagonal head, a long tail, and a base plate. b Electron microscopic image of the M4 phage shows that it has a long contractile tail (arrow). M4 thus belongs to the Myoviridae family.

tion and plating method. Phages with a high thermostability have better chances of survival in different conditions where the temperature may rise to $70^{\circ} \mathrm{C}$. Figure $2 \mathrm{a}$ shows the kinetics of thermal inactivation of the phage M4 at different temperatures. Slow inactivation was observed in the $40-60^{\circ} \mathrm{C}$ range while rapid inactivation was observed above $60^{\circ} \mathrm{C}$. It can be concluded that M4 is a thermotolerant phage as the half-life was calculated to be around $8.5 \mathrm{~min}$ at $60^{\circ} \mathrm{C}$ in comparison with the other vibriophages like $\mathrm{S} 20$, which has a half-life of 4.5 at $60^{\circ} \mathrm{C}$.

El Tor Vibriophage M4
$\mathrm{pH}$ is an important physiological parameter for any living cell, $\mathrm{pH}$-intolerant phages have limited use for therapeutic purposes. In this study the $\mathrm{pH}$ stability of the phage was determined by adding the phage samples in LB broths whose $\mathrm{pH}$ were adjusted to a range of 3-13 and incubating at $37^{\circ} \mathrm{C}$ for $1 \mathrm{~h}$. Surviving phages were assayed via the dilution and plating method. Vibriophages are usually found to be more stable in alkaline $\mathrm{pH}$ than in acidic $\mathrm{pH}[12,13]$. Interestingly, for the M4 phage it was observed that alkali had a more inactivating effect than 
Table 1. Comparison between different El Tor vibriophages

\begin{tabular}{llllll}
\hline Characteristic & M4 & S20 & S5 & N4 & D10 \\
\hline Family & Myoviridae & Podoviridae & Podoviridae & Podoviridae & $\begin{array}{l}\text { Myoviridae } \\
\text { short tail }\end{array}$ \\
Tail morphology & long contractile tail & short tail & $57.5 \pm 2.3$ & $72.1 \pm 1.4$ & $52 \pm 2.3$ \\
Capsid size, nm & $85 \pm 3$ & $58.6 \pm 1.7$ & $8.3 \pm 1.1$ & $9.70 \pm 2.0$ & $101.4 \pm 0.3$ \\
Tail size, nm & $98 \pm 2$ & $11.5 \pm 1.8$ & $39.2 \pm 2.7$ & 38.4 & 32 \\
Genome size, kb & 120 & $40.7 \pm 1.5$ & 15 and 25 min & - & - \\
Eclipse and latent periods & 15 and 30 min & 10 and 12 min & more stable in alkali & - & - \\
pH stability & more stable in acids & more stable in alkali & & & \\
\hline
\end{tabular}

acid (Fig. 2b). The survival graph of this phage shows that at $\mathrm{pH} 10.0$ the survival percentage is around 30 , whereas below $\mathrm{pH} 5.0$ the survival percentage is around 40. The phage was found to be stable (more than $90 \%$ survival after $1 \mathrm{~h}$ ) in the $\mathrm{pH}$ range of 5.0-8.0.

Ultraviolet light is extensively used to inactivate microbes including phages. It produces some important physiological and genetic effects which can result in genetic recombination and exert a mutagenic action. For this study, phage M4 $\left(10^{9} \mathrm{pfu} / \mathrm{mL}\right)$ was exposed as a thin layer ( $1 \mathrm{~mm}$ thick) in a plastic petri dish with constant shaking under a 15-W Philips germicidal lamp emitting primarily 254-nm UV and at a distance of $50 \mathrm{~cm}$. Samples were removed every $5 \mathrm{~s}$ and assayed for surviving phages. UV inactivation was found to obey the first-order reaction kinetics (Fig. 2c). The time required for 37\% (D37) and $10 \%$ (D10) survival of the M4 phage was found to be 5 and $12 \mathrm{~s}$, respectively. Therefore, UV has same inactivating effect on as on other phages as $90 \%$ of phages were inactivated within $12 \mathrm{~s}$ of UV exposure.

For morphological and genomic studies by electron microscopy, the phage sample was negatively stained with $2 \%$ uranyl acetate and imaged with an FEI Tecnai 12 BioTwin transmission electron microscope operating at $120 \mathrm{kV}$ and a magnification of $\times 30,000$ on KODAK 4489 films. The films were scanned with a NIKON supercool 9,000 scanner at 2,000 dpi. The electron microscopic image of the negatively stained phage showed that it has a hexagonal head and a long tail (Fig. 3a) like T4 [17]. The diameter of the head was $85 \pm 3 \mathrm{~nm}$, which is quite big compared to other vibriophages (Table 1). The length of the tail was $98 \pm 2 \mathrm{~nm}$ and the diameter of the tail was about $42 \pm 3 \mathrm{~nm}$. The tail was shown to be constricted in the head-to-tail connecting region and bulged out at the base. The tail has a prominent base plate and a head-totail connector. The baseplate measured around $28 \pm 2 \mathrm{~nm}$ in diameter. The tail of the phage M4 is contractile in nature as shown in Figure 3b. When contracted, the length of the tail sheath was measured to be around $48 \pm$ $3 \mathrm{~nm}$, which is about half of the length of the uncontracted tail core. The diameter of the tail sheath when contracted was around $45 \pm 2 \mathrm{~nm}$. The magnification was calibrated using beef catalase crystal. According to the ICTV (International Committee on Taxonomy of Viruses) classification system based on the tail morphology of phages, this M4 phage therefore belongs to the Myoviridae family.

For electron microscopy of the genome, the singlestep release method of Kleinschmidt et al. [18] was employed. Briefly, the phage sample was incubated with high molar ammonium acetate followed by mixing with cytochrome $\mathrm{C}$ and then spread on double-distilled water. The DNA-bound protein monolayer was picked up on a carbon-coated grid, stained with alcoholic uranyl acetate [19], and rotary-shadowed with platinum. pBR322 DNA was added to the phage mixture as an internal calibration standard. Electron microscopy of the genome showed that M4 has a linear DNA (Fig. 4) and the length of the DNA is about $120 \mathrm{~kb}$, which corresponds to a molecular weight of about $80 \mathrm{MDa}$. A previous study showed that the genome of M4 can be cut with restriction endonuclease HindIII [10], confirming the genome to be doublestranded DNA. This phage M4 has a very large DNA, i.e., about 3 times more than another myoviridae vibriophage D10 (Table 1). In all DNA phages the chromosome is highly condensed within the capsid and represents about $20-50 \%$ of its mass [20]. The DNA inside of the capsid is packaged in a highly dense manner and the density of the packaged DNA is dependent on the Vm that describes the volume occupied per Dalton of biological macromolecule [21]. This relative packaging density of DNA or RNA within the phage head also provides a quantitative parameter for comparing viruses. A low Vm value indicates a high packaging density of the genome 


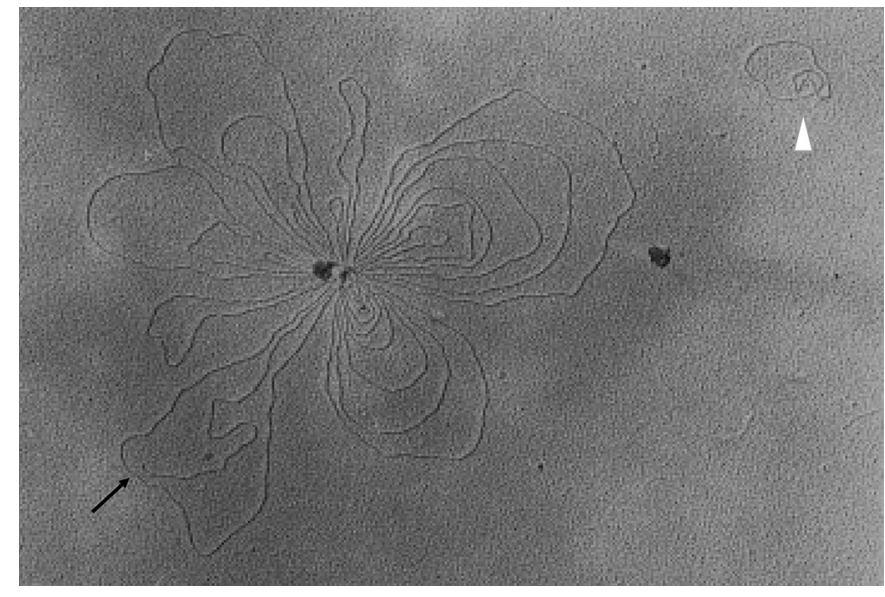

Fig. 4. Electron micrograph of vibriophage M4 DNA. The DNA is linear (end marked by an arrow) and has a length of around 120 $\mathrm{kb}$. The small circular DNA at the top right (arrowhead) is pBR322 DNA (4.361 kb), used as an internal marker.

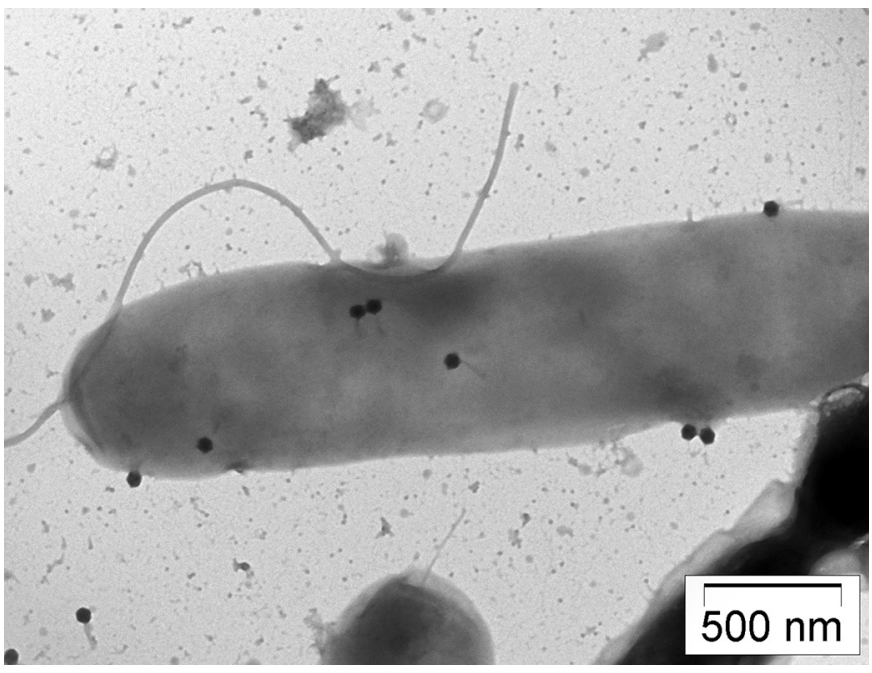

Fig. 5. Negatively stained image of M4 phage-infected El Tor $V$. cholerae MAK757. The intact phages are clearly seen attached to the host after 5 min of incubation.

inside a phage head. The $\mathrm{Vm}$ value for any phage can be calculated using the following formula: volume of the container $\left(\AA^{3}\right)$ /molecular weight of the macromolecule (Da), as described in the paper by Johnson and Rueckert [21]. For the M4 phage the volume (Vc) of the inner capsid, which is considered the container, is calculated to be $1.4 \times 10^{8} \AA^{3}$ according to the following equation: $\mathrm{Vc}=$ $0.718 b^{2} \mathrm{Lc}-0.322 \mathrm{~b}^{2}[22]$, where $\mathrm{Lc}$ is the longest inner diameter and $b$ is the shortest inner diameter of the phage capsid. The $L c$ and $b$ values for this phage were measured as 630 and $566 \AA$, respectively. The molecular weight of the DNA was calculated to be $8 \times 10^{7} \mathrm{Da}$. Therefore, the Vm value for this M4 phage was calculated as $1.75 \AA^{3} / \mathrm{Da}$. This is low compared to viruses like the southern bean mosaic virus, the satellite tobacco necrosis virus, and some other viruses [21], leading to the conclusion that there is a very high packaging density of the genome inside the head.

The phage-bacterial interaction study by negative staining was done to determine the adsorption time and lysis time by infecting $250 \mu \mathrm{L}$ of the bacterial strain with $100 \mu \mathrm{L}$ of $10^{8} \mathrm{M} 4$ phage and incubating it at room temperature for $5 \mathrm{~min}$ without shaking. After incubation $5 \mu \mathrm{L}$ of the above mixture was deposited on a grid, negatively stained with uranyl acetate, and imaged using an electron microscope. The image (Fig. 5a) shows that multiple phages with intact tails are attached to the bacteria but the phage DNA is still not released. To study the bacteriaphage interaction, an ultrathin sectioning technique was employed. Briefly, aliquots of bacteria-phage suspension were taken and incubated for different time periods, i.e., $5,10,20$, and $30 \mathrm{~min}$. The aliquots were then double-fixed with $3 \%$ glutaraldehyde and $1 \%$ osmium tetroxide, dehydrated in a graded series of acetone, and embedded in Agar 100 resin. Ultrathin sections were cut in a Leica Ultracut ultramicrotome and double-stained with uranyl acetate and lead citrate, and sections were analyzed by transmission electron microscopy. Figure 6a shows how an intact phage after $5 \mathrm{~min}$ of incubation with bacteria is attached to the bacteria and about to release its DNA. However, the image of the phage-infected bacteria after 10 min of incubation shows that the phage has delivered its genome inside host (Fig. 6b) but does not start lysis as the integrity of the bacteria is maintained. This observation shows that the eclipse period of this phage must be above $10 \mathrm{~min}$. The ultrathin section (Fig. 6c) of infected bacteria after $30 \mathrm{~min}$ of incubation with the phage shows that the phage has started lysing the bacteria; therefore, the bacterial membrane is seen to be disrupted and other cellular materials are also disorganized, indicating lysis of the bacteria.

From Table 1 it is evident that among the 5 newly isolated phages [10] M4 has many features that differentiate it from others. Considering the size it has a big head among all of the phages. Phages with a big head are very interesting subjects of further study. In case of sustainability it also shows variation in that, unlike other vibriophages, it is stable in acidic conditions in comparison to the alkalis, which is useful information regarding its sta- 


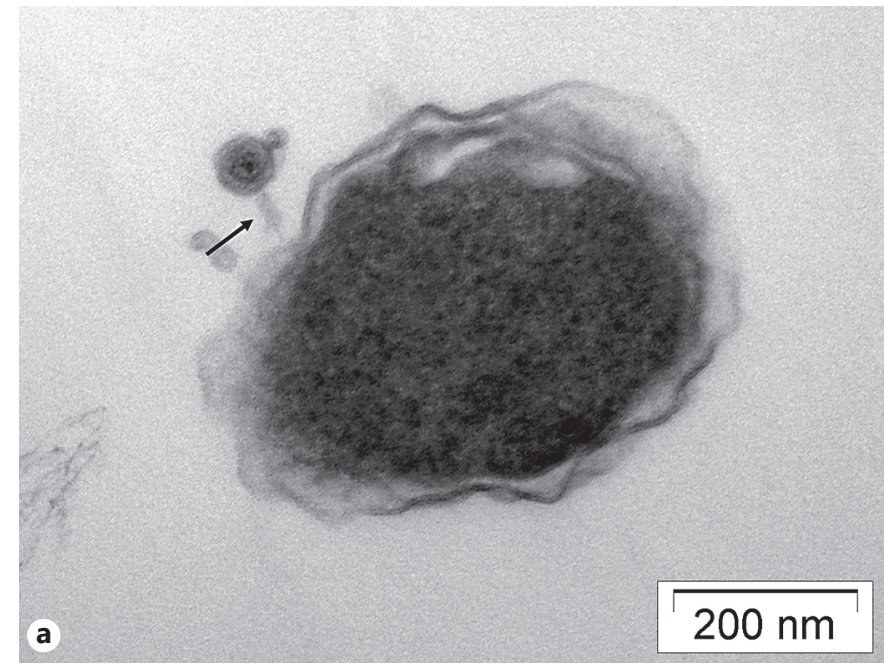

Fig. 6. Ultrathin section of the El Tor $V$. cholerae strain MAK757 infected with the M4 phage at different incubation times: $5 \mathrm{~min}$, the phage (arrow) is seen to be releasing its genome (a); $10 \mathrm{~min}$, empty phage capsids are seen attached to the bacteria (b); and 30 min, lysis of the bacteria at the end of phage formation is prominent as the membrane and cellular materials of the bacteria are disorganized (c).

bility in the acidic stomach as a therapeutic agent in future. The genome size of this phage is also the highest among all of the 5 newly isolated vibriophages. The large head is therefore needed to accommodate such a large genome. Moreover, studies on this novel El Tor vibriophage M4 using physicochemical methods and conventional transmission electron microscopy have enlightened us with information regarding different physiological, morphological, and physicochemical parameters of a vibriophage which will help us to assess its usefulness as a therapeutic agent.
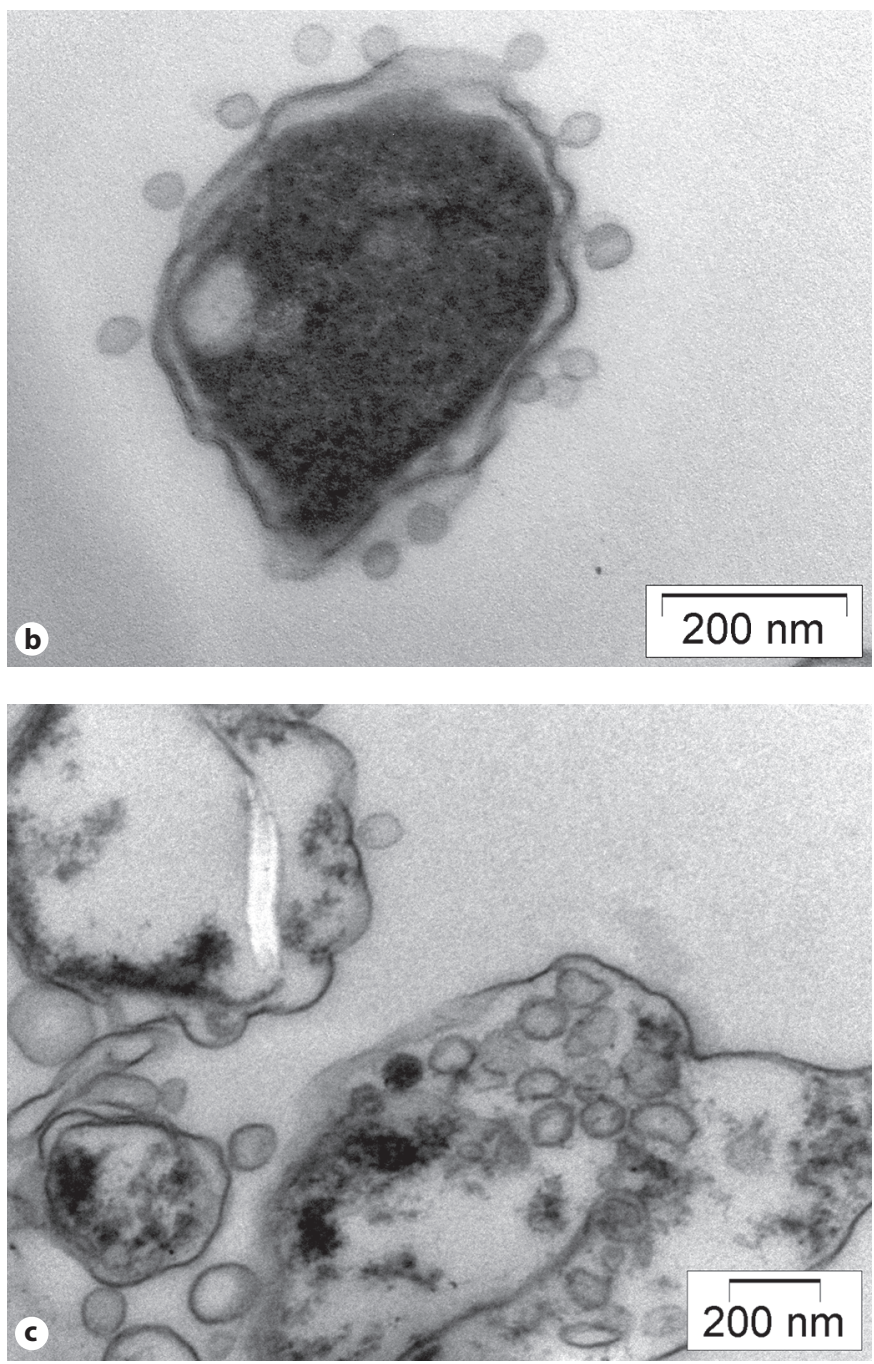

\section{Acknowledgement}

We are thankful to Dr. Shanta Dutta, the director of this institute, for her interest in and kind support of this study. Financial assistance from CSIR of the Government of India (grant No. 21 [0948]/13/EMR-II) is gratefully acknowledged.

\section{Ethics Statement}

We did not use any humans or animals in this study.

\section{Disclosure Statement}

We have no conflict of interests to disclose. 


\section{References}

1 World Health Organization: Cholera. 2017. http://www.who.int/mediacentre/factsheets/ fs $107 /$ en/.

2 Ali M, Nelson AR, Lopez AL, Sack D: Updated global burden of cholera in endemic countries. PLoS Negl Trop Dis 2015;9:e0003832.

3 Finkelstein RA: Cholera, Vibrio cholerae O1 and O139, and other pathogenic vibrios; in Samuel B (ed): Medical Microbiology. Galveston, University of Texas Medical Branch, 1996.

4 Robbins WP, John JM: Genomic science in understanding cholera outbreaks and evolution of Vibrio cholerae as a human pathogen. Curr Top Microbiol Immunol 2014;379:211229.

5 Siddique AK, Baqui AH, Eusof A, Haider K, Hossain MA, Bashir I, Zaman K: Survival of classic cholera in Bangladesh. Lancet 1991; 337:1125-1127.

6 Satchell KJ, Jones CJ, Wong J, Queen J, Agarwal S, Yildiz FH: Phenotypic analysis reveals that the 2010 Haiti cholera epidemic is linked to a hypervirulent strain. Infect Immun 2016; 84:2473-2481.
7 Sjölund KM, Reimer A, Folster JP, Walker M, Dahourou GA, Batra DG, Martin I, Joyce K, Parsons MB, Boncy J, Whichard JM, Gilmour MW: Drug resistance mechanisms in V. cholerae O1 outbreak strain, Haiti, 2010. Emerg Infect Dis 2011;17:2151-2154.

8 Hall SL, Costerton JW, Stoodley P: Bacterial biofilms: from the natural environment to infectious diseases, Nat Rev Microbiol 2004;2: 95-108.

9 Chanishvili N: Phage therapy - history from Twort and d'Herelle through Soviet experience to current approaches. Adv Virus Res 2012;83:3-40.

10 Chattopadhyay DJ, Sarkar BL, Ansari MQ, Chakrabarti BK, Roy MK, Ghosh AN, Pal SC: New phage typing scheme for Vibrio cholerae O1 biotype El Tor strains. J Clin Microbiol 1993;31:1579-1585.

11 Adams MH: Bacteriophages. New York, Wiley, 1963.

12 Dutta M, Ghosh AN: Physicochemical characterization of El Tor vibriophage S20. Intervirology 2007;50:264-272.

13 Mitra K, Ghosh AN: Characterization of Vibrio cholerae $\mathrm{O} 1 \mathrm{El}$ Tor typing phage S5. Arch Virol 2007;152:1775-1786.

14 Basu R, Ghosh AN, Dasgupta S, Ghosh A: Biophysical characterization of vibrio El Tor typing phage e5. FEMS Microbiol Lett 1993; 106:9-16.
15 Stent GS: Molecular Biology of Bacterial Viruses. San Francisco, Freeman, 1963.

16 Chatterjee SN, Maity M: Vibriophages and vibriocins: physical, chemical and biological properties. Virus Res 1984;29:263-312.

17 Yap ML, Rossmann MG: Structure and function of bacteriophage T4. Future Microbiol 2014;9:1319-1327.

18 Kleinschmidt AK, Lang D, Jacherts D, Zahn RK: Darstellung und Längenmessungen des gesamten Desoxyribonucleinsäure-Inhaltes von T2-Bakteriophagen. Biochim Biophys Acta 1962;61:857-864.

19 Coggins LW: Preparation of Nucleic Acids for Electron Microscopy in Electron Microscopy in Molecular Biology. Washington, IRL Press, 1987.

20 Earnshaw WC, Harrison SC: DNA arrangement in isometric phage heads. Nature 1977; 268:598-602.

21 Johnson J, Rueckert R: Packaging and Release of the Viral Genome in Structural Biology of Viruses. New York, Oxford University Press, 1997, vol 10, pp 269-287.

22 Klimenko SM, Tikchonenko TI, Andreev VM: Packing of DNA in the head of bacteriophage T2. J Mol Biol 1967;23:523-533. 